\title{
Does Work at Fuel Station for Long Period Affect Leukocytes Count?
}

\section{Rana Zaini' ${ }^{*}$, Haytham Dahlawi ${ }^{2}$, Sara Al-Shehri ${ }^{3}$, Mariam} Al-Fahmi ${ }^{3}$, Jawaher Khaled ${ }^{3}$, Norah Al-Barakah ${ }^{3}$ and Wojdan Ahmed Al-Sayyali ${ }^{3}$

${ }^{1}$ Dean, Deanship of Community Service and Sustainable Development, Associate Professor in Haematology, Taif University, Taif, Saudi Arabia

${ }^{2}$ Vice-dean College of Applied Medical Science, Associate Professor in Haematology, Taif University, Taif, Saudi Arabia

${ }^{3}$ Student at Clinical Laboratory Department, College of Applied Medical Science, Taif University, Taif, Saudi Arabia

*Corresponding Author: Rana Zaini, Dean of Deanship of Community Service and Sustainable Development, Associate Professor in Haematology, Taif University, Taif, Saudi Arabia.
Received: May 09, 2020

Published: June 15, 2020

(C) All rights are reserved by Rana Zaini., et al.

\section{Abstract}

Exposure to benzene has been significantly associated with many health disorders and reported to cause abnormality in hematological parameters; haemoglobin (Hb) concentration, red blood cells (RBCs) and white blood cells (WBC) level. Thus, the aim of this study was to evaluate the association between exposure to benzene for a long period of time (more than 12 months with daily 8-hour time) and the level of hematological parameters among fuel station workers at Taif city in Western region of the Saudi Arabia. This case-control study involved thirteen participants ( 10 fuel station workers and three control individuals) aged between 25 to 45 years. Three healthy individuals were considered as control group. The result of this study showed normal level of all haematological parameters including haemoglobin ( $\mathrm{Hb}$ ), red blood cells (RBCs), white blood cells and platelets when complete blood count (CBC) was investigated for ten workers. Moreover, the level of neutrophils and lymphocytes were reported within the normal ranges. We conclude that benzene exposure had no effects on haematological parameters among workers who exposed to benzene for long period of time when compared to the control group. However, further study are required to confirm these finding with larger sample size.

Keywords: Exposure; Benzene; Haemoglobin; Red Blood Cells; White Blood Cells Level; Taif

\section{Abbreviations}

Hb: Haemoglobin; RBCs: Red Blood Cells; WBC: White Blood Cells; CNS: Central Nervous System; DNA: Deoxyribonucleic Acid; CBC: Complete Blood Count

\section{Introduction}

Benzene is an organic chemical compound classified as a hydrocarbon [1]. Benzene is generated from both natural processes and human activities. Natural sources of benzene include emissions from fires. Benzene is also a natural part of crude oil and gasoline. Moreover, it is reported as a main factor for air pollution [2]. According to the World Health Organization (WHO) benzene was ranked as the first class material [3].

This chemical can be absorbed into the body by inhalation, direct contact to the skin and ingestion. It has been found that the inhalation of benzene is a common way of benzene absorption into the body and may cause different health and respiratory disorders. In addition, contacting with injured skin increase the chance of benzene absorption and may cause variant dermatological problems. Ingestion is another way for benzene absorption. The quantity and duration of benzene exposure as well as the age of exposed individual were highly associated with the severity of health complications. Several research studies reported that benzene exposure is associated with damaging human systems and organs. Some of the human systems that affected by exposure to benzene are respiratory system, central nervous system (CNS), blood cells synthesis and immunity [4]. Cell death in liver, heart, kidney and skin was reported as a main cause of human's organs harmful. Skin contact with gasoline may cause rash, redness, and swelling [5]. Other symptoms can be seen such as; headache, vertigo, morning cough, and shortness of breathing [6]. 
Different studies stated that many of the serious effects might be seen after gasoline's exposure were related to the separate chemicals in the gasoline mixture, such as benzene, lead, and oxygenates [6-8]. Bone marrow failure was found to be one of the serious health problems of benzene exposure which, impair blood cells formation such as red and white blood cells. Other research studies suggested that benzene-induced toxicity involves several mechanisms, for instance DNA (deoxyribonucleic acid) damage, programmed cell death, oxidative stress and disruption of the cell cycle. In 2013, it has been revealed that exposure to benzene may affect hematopoietic system, central nervous system (CNS) and reproductive system. Within the same study they found that benzene exposure could increase the risk of developing cancer [9]. Another study showed that low dose of benzene exposure increase the risk of acute myelogenous leukaemia (AML) by changing in DNA methylation patterns [10]. On the other hand, $\mathrm{Al}$ Jothery and Al- hassnwi found unclear association between the effects of low levels benzene exposure and health complications [6].

Chronic and long period exposure to benzene was found to be associated with progressive degeneration of the bone marrow [7]. A major effect of long-term benzene exposure was seen on the blood cells morphology and structure. In 2015, a cross sectional study showed a significant decrease in haemoglobin $(\mathrm{Hb})$ and red blood cells (RBCs) levels among fuel stations workers [11]. Besides causing anaemia, it can also cause excessive bleeding, increase the chance of infection and has a role in causing human leukemia. There is a significant harmful health effects on human exposure to benzene and might be associated with the risk of blood abnormalities, including aplastic anemia, leukemia, lymphoma, pancytopenia and chromosomal aberrations. However, exact pathophysiology of hematological effects following exposure to benzene still unclear [11].

One of the most important clinical laboratory investigations to detect the effect of benzene exposure on blood level and abnormality is complete blood count (CBC) [3]. Such blood test can provides valuable information about the quantity of the different types of cells in the blood. The test might help in diagnosing several haematological disorders e.g. anaemia. Complete blood count is known as a quick, easy and accessible screening for checking the haematoxicity of benzene [11].

In Taif, no research was performed before to detect the association between benzene exposure and changing hematological parameters. Thus, this study aims to assess the relationship between exposure to benzene for long period of time and the level of hematological parameters in male gasoline workers aging between 25 to 45 years old. Also, to compare the $\mathrm{CBC}$ results for any differences between gasoline workers and control group of healthy individuals.

\section{Materials and Methods}

This case-control study performed from December 2019 to February 2020. Thirteen samples (3 control samples) were collected at the first seven weeks of the study, all samples were collected randomly from healthy males adult aged between 25 - 45 years. Ten participants were working at six different fuel stations and had been working for more than twelve months with daily 8-hour time at various areas in Taif city, Western region of the Kingdome. Three control samples were collected from healthy individuals. Data was collected by questionnaire. All participants completed individual informed consent forms.

A volume of $3 \mathrm{~mL}$ of venous blood samples were collected using disposable syringes in Ethylenediamine tetraacetic acid (EDTA) tube, which contains anticoagulant to prevent clot formation and maintain blood in the fluid state. The collected samples from both fuel stations as well as control group were sent immediately to the lab for performing complete blood count (CBC) test. Hemoglobin (Hb), red blood cells (RBCs), white blood cell count (WBC), counts of neutrophils, lymphocytes, monocytes, and platelets were investigated. Each sample was run twice to confirm the result of each participant. Inclusion criteria were including; individuals with infection (typhoid, malaria, pharyngitis, etc.), any systemic disease or allergies (hypertension, diabetes mellitus, rheumatoid arthritis, etc.), and using medications affecting blood counts. Also, workers for less than 12 months were excluded in this study.

\section{Statistical analysis}

Data were entered and statistically analyzed using the Statistical Package for Social Sciences (SPSS) version 17.

\section{Ethical concerns}

The participants (fuel stations workers and control group) were informed about the aim of the study before sample collection. Information about anonymity, confidentiality and consent were included in the explanation.

\section{Results and Discussion}

This study was performed on ten healthy male working at fuel stations and aged between 25 to 45 years old. All participants were working at fuel station at Taif city for at least twelve months. Also, samples from three healthy individuals were collected in this study as a control group. The results of control group showed normal values according to the world health organization (WHO) criteria for all the haematological parameters (Table 1). This study showed also normal concentration for haemoglobin $(\mathrm{Hb})$ and normal level of red blood cells (RBCs), white blood cells (WBCs) and platelets among all participants. The result of platelet count was also nor- 


\begin{tabular}{|l|c|c|c|c|c|c|}
\hline Control patient & Hb (g/dL) & RBC (uL) & WBC (uL) & PLT (uL) & NEU \% & LYM \% \\
\hline 1 & 14.6 & 5.04 & 6.71 & 166 & 50.9 & 38.7 \\
\hline 2 & 15.0 & 5.42 & 4.09 & 251 & 38.6 & 50.4 \\
\hline 3 & 15.5 & 5.33 & 3.80 & 266 & 37 & 50 \\
\hline
\end{tabular}

Table 1: The results of complete blood count (CBC) for hematological parameters among control group. Normal range of $\mathrm{Hb}=12.2-18.1 \mathrm{~g} / \mathrm{dL}, \mathrm{RBCs}=4.04-6.13 \mathrm{uL}, \mathrm{WBCs}=4-11 \mathrm{uL}, \mathrm{PLT}=145-450 \mathrm{uL}, \mathrm{NEU}=37.0-80.0 \%, \mathrm{LYM}=10.0-50.0 \%$.

\begin{tabular}{|c|c|c|c|c|c|c|}
\hline Patient & Hb (g/dL) & RBC (uL) & WBC (uL) & PLT (uL) & NEU \% & LYM \% \\
\hline 1 & 16.2 & 5.6 & 10.1 & 234 & 69 & 27 \\
\hline 2 & 16.0 & 5.5 & 10.1 & 173 & 60 & 34 \\
\hline 3 & 17.9 & 5.9 & 10.8 & 318 & 57 & 37 \\
\hline 4 & 16.4 & 6.0 & 8.2 & 256 & 51 & 43 \\
\hline 5 & 17.0 & 5.7 & 8.9 & 258 & 51 & 41 \\
\hline 6 & 16.4 & 5.3 & 9.5 & 222 & 45 & 49 \\
\hline 7 & 17.5 & 5.8 & 8.6 & 244 & 44 & 50 \\
\hline 8 & 16.2 & 5.6 & 5.8 & 259 & 37 & 49 \\
\hline 9 & 15.2 & 5.0 & 10.0 & 198 & 63 & 31 \\
\hline 10 & 16.7 & 5.7 & 7.3 & 207 & 49 & 44 \\
\hline
\end{tabular}

Table 2: The results of complete blood count (CBC) for hematological parameters among gasoline participants workers. Normal range of $\mathrm{Hb}=12.2-18.1 \mathrm{~g} / \mathrm{dL}, \mathrm{RBCs}=4.04-6.13 \mathrm{uL}, \mathrm{WBCs}=4-11 \mathrm{uL}, \mathrm{PLT}=145-450 \mathrm{uL}, \mathrm{NEU}=37.0-80.0 \%, \mathrm{LYM}=10.0-50.0 \%$.

mal. In addition, the level of the most predominant white blood cells neutrophils and lymphocytes were within the normal ranges (Table 2).

Benzene exposure was highly associated with various health problems targeting different human systems and organs. Some of the human systems that might be affected by exposure to benzene are respiratory, CNS and body's immune system. Moreover, human's organs can be also affected leading to cell death in heart, liver and kidney. Following gasoline exposure many health complications and disorders can be seen due to the individual chemicals in the gasoline mixture, such as benzene. It has been found that breathing small amounts of gasoline vapors were associated with breathing difficulties, nausea, vomiting, nose and throat irritation, headaches, dizziness and confusion [5]. More serious effect was seen on blood cells production and synthesis $[4,7]$.

The result of this study showed normal level of all haematological parameters; haemoglobin (Hb), red blood cells (RBCs), white blood cells (WBCs) and platelets among ten gasoline workers when complete blood count was performed and compared to the control healthy individuals (control group). Moreover, the level of neutrophils and lymphocytes were reported within the normal ranges. Similar to our finding Tsai and colleagues (2004) did not find any haematological effects between benzene-exposed work- ers and control group [12]. Another study showed similar results, when total white blood cells, red blood cells, hemoglobin, mean corpuscular volume and platelets were examined among workers exposed to low levels of benzene showed no differences when compared to healthy individuals [13].

However, in Baghdad a study found significant decrease in haemoglobin level, WBCs, and RBCs counts among petrol station workers [8]. More recent study was done in 2016 has showed an increased RBC count and $\mathrm{Hb}$ concentration among thirty healthy male petrol pump workers aged 20 - 50 years [14]. Moreover, in 2005 , it has been found that significantly declined at WBCs, neutrophils, lymphocytes, and platelets level with increasing benzene exposure among workers exposed to benzene compared to unexposed controls persons [15]. The possible explanation for differences between the result of our study and the others is might be the dose of exposure to benzene, period of exposure, and the level of environmental benzene pollution.

\section{Study Limitation}

This study has some limitations. There was small sample size for the study participants due to the limited time for the research study. Also, few locations where the fuel station located at Taif city were involved, some more locations are required to be included. 


\section{Conclusion}

This study conclude that benzene exposure has a no potential effect to induce on hematological parameters alterations among individuals working at fuel stations in Taif city at Saudi Arabia. The results of this study reported normal concentration of hematological biomarkers in workers at fuel stations exosed to benzene compared to the control group (unexposed individuals).

\section{Acknowledgements}

The authors are grateful to all participants at western region of Saudi Arabia who participated in this study.

\section{Conflict of Interest}

The authors have no conflict of interests to disclose

\section{Bibliography}

1. Yoon JH., et al. "A brief review of relationship between occupational benzene exposure and hematopoietic cancer". Annals of Occupational and Environmental Medicine 30.1 (2018): 33.

2. El-Gohary AE., et al. "Biological assessment of exposure to benzene among patrol stations' workers in Zagazig City by using Trans, Trans-Muconic acid as urinary indicator". Egyptian Journal of Occupational Medicine 34.2 (2010): 171-181.

3. WHO. Air quality guidelines for Europe. $2^{\text {nd }}$ Edition. Eu. WHO Regional publication (2006).

4. Mohammad NM A. "Relationship between exposure to petrol products and the trace metal status, liver toxicity and hematological markers in gasoline filling workers in Sulaimani city". Journal of Environmental and Occupational Science 1.1 (2012): 6-11.

5. Carletti R and Romano D. "Assessing health risk from benzene pollution in an urban area". Environmental Monitoring and Assessment 80.2 (2002): 135-148.

6. Al Jothery AHT and Al- hassnwi AT. "Changes in the hematological profile among workers at patrol stations in Babil Province/Iraq". Mesopotamia Environmental Journal 3.4 (2017): 25-32.

7. Abraham NG. "Hematopoietic effects of benzene inhalation assessed by long-term bone marrow culture". Environmental Health Perspectives 104.6 (1996): 1277-1282.

8. Sahb A. "Hematological assessment of gasoline exposure among petrol filling workers in Baghdad". Journal of the Faculty of Medicine Baghdad 53.4 (2011): 369-400.
9. Tunsaringkarn T., et al. "Occupational exposure to benzene and changes in hematological parameters and urinary trans, trans-muconic acid". Journal of Occupational and Environmental Medicine 4.1 (2013): 45-49.

10. Bollati V., et al. "Changes in DNA methylation patterns in subjects exposed to low-dose benzene". Cancer Research 67.3 (2007): 876-880.

11. Elderdery AY., et al. "Alteration in hematological parameters among workers of fuel stations in White Nile State, Sudan". International Journal of Biomedical and Advance Research 6.11 (2015): 780-784.

12. Tsai SP., et al. "A hematology surveillance study of petrochemical workers exposed to benzene". Regulatory Toxicology and Pharmacology 40.1 (2004): 67-73.

13. Collins JJ., et al. "Evaluation of lymphopenia among workers with low-level benzene exposure and the utility of routine data collection". Journal of Occupational and Environmental Medicine 39.3 (1997): 232-237.

14. Mistry HA., et al. "Study of red blood cell count, hemoglobin concentration, and platelets in petrol pump workers of Surat city". National Journal of Physiology, Pharmacy and Pharmacology 6.2 (2016): 167-169.

15. Qing L., et al. "Hematotoxicity in Workers Exposed to Low Levels of Benzene”. Science 306.5702 (2005): 1774-1776.

\section{Assets from publication with us}

- Prompt Acknowledgement after receiving the article

- Thorough Double blinded peer review

- Rapid Publication

- Issue of Publication Certificate

- High visibility of your Published work

Website: www.actascientific.com/

Submit Article: www.actascientific.com/submission.php Email us: editor@actascientific.com

Contact us: +919182824667 